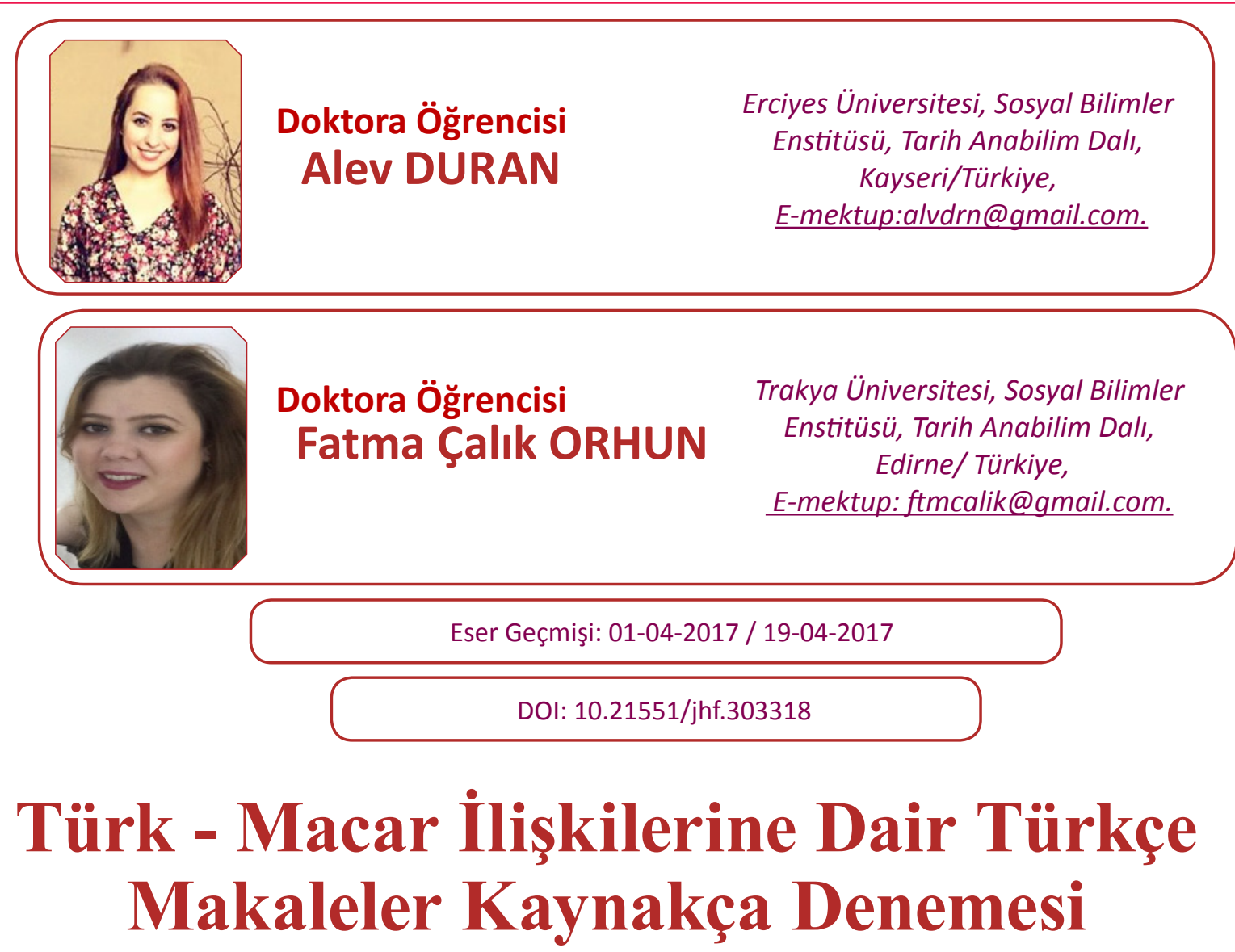

\title{
A Bibliography Attempt Of Turkish Articles Written On The Turkish- Hungarian Relationship
}

\section{ÖZET}

$\mathrm{Bu}$ çalışmada, Macar ve Türk ilişkileri ile ilgili kaleme alınmış Türkçe makaleleri kapsamakta olup hatıratlar, yüksek lisans ve doktora tezleri ile araştırma eserleri kapsam dışında bırakılmıştır. Yazar soyadlarının alfabetik olarak sıralandığı kaynakça, Türkçe süreli yayınlar, çeşitli bildiri kitapları ve veri tabanları taranarak oluşturulmuştur.

Anahtar Kelimeler: Türk-Macar İlişkileri, Bibliyografya, Macaristan

\section{ABSTRACT}

This study covers articles in Turkish written about the Turkish- Hungarian relationship, but the master and doctorate theses were excluded from the scope of there search. The bibliography where author sare listed alphabetically by surname are formed by surveyig periodicals, various report boks and other databases.

Keywords:Turco-HungaryRelations, Bibliography, Hungary 


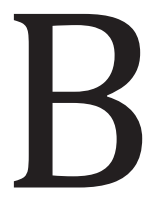
ilimsel bir araştırmada, bir konu üzerinde çalıșmaya başlamadan önce, o konuyla ilgili olarak yapılan çalışmaların tespit edilmesi ilk adım olmakla birlikte olmazsa olmaz bir aşamayı ifade eder. Çalışılan konunun bilimsel bir yapıya sahip olması için, bu ilk aşamada yeterli malzemenin ortaya konulması gereklidir.

Hazırlanacak çalışma öncesi bilgi arama ve toplama sürecinde tarihçiler arasında genelde ilgili konuda yayınlanmış kitap ve makalelerdeki dipnotların takibi en çok tercih edilen yöntem olmakla birlikte basılı bibliyograflar ve toplu kataloglar da kullanılmaktadır. ${ }^{1}$ Birçok tarihçi çalışma alanlarıyla ilgili toplu bibliyografyalar eksik olduğu ve de bilgiye ve kaynaklara ulaşmada görülen zorluklar nedeniyle kendi künye çalışmalarını yapmakta, kendi kütüphane ve arşivini oluşturma çabası içerisine girmektedir.

Hakkında bibliyografik çalışmalar yapılmamış kaynaklara erişim çoğu zaman tesadüfi olmaktadır. Bu yüzden bibliyografya çalışmaları araştırmacılara kolaylıklar sağladığı gibi, araştııılmayan konuların ortaya çıkarılmasına katkı da sağlamaktadır.

Günümüzde zamanın son derece önemli olduğu göz önüne alındığında, araștırmacıların çok fazla zaman alan bir süreçten, yani kaynak tarama sürecinden tasarruf etmelerine neden olmaktadır. Zaten bilgiye ulaşmanın birçok zorlukları hatırlandığında, en azından kaynak taraması sürecinde tasarruf, araştırmacının esas dikkatini vermesi gereken analiz, sentez ve tahlil aşamalarına daha fazla zaman ayırmaları açısından önemli olacaktır.

Geniş anlamıyla bibliyografyayı tanımlayacak olursak eğer, her biçimdeki materyalin listesi olarak tanımlamak mümkündür. Bibliyografyanın ilk işlevi ise, kayıtlı bilgiyi tek tek listelemek; amacı ise bilginin varlığından haberdar etmektir. Bir bibliyografya, belirli bir ülkede, yayımlanmış, belirli bir konuda, belirli bir biçimde ya da içeriği birçok başka faktörle sınırlandırılabilen materyalleri listeleyebilir. Bibliyografyalar basılı ya da bilgisayar veri tabanları șeklinde olabilir. ${ }^{2}$

Çalışmamızın konusuna gelecek olursak, Macar tarihi, Türk tarihinin önemli bir parçasını oluşturmaktadır.V. Yüzyıldan itibaren temasta olduğumuzve 1526 Mohaç zaferi ile Osmanlının Macaristan'ayerleșmesiyle uzun süre Türk egemenliğinde kalan Macarlar ve Türkler arasındaki ilişkiler tarih boyunca süregelmiş ve her iki taraf için de önemli bir araştırma alanı olmuștur. Batılı kaynakların Macarlardan başlarda Türk olarak bahsetmesi ve Macar tarihinde bir Hun-Macar akrabalığı efsanesi bulunması, özellikle 19. yüzyıl ve 20. yüzyıl başı romantik milliyetçilerinde (hem Macaristan'da, hem de Türkiye'de) Türklerle Macarların akraba oldukları inanışını doğurmuştur.

$\mathrm{Bu}$ inanışlar, yüzyıllardan süregelen ilişkiler, Macarların kendi köken ve dillerine dair merakları ve çeşitli teoriler vasıtasıyla hem Macarlar hem de Türkler bu iki millet arası ilişkileri araştırmış ve araştırmaya devam edecektir. Bu çalışmamızda tükenmez bir

1 Hatice Gülșen Birinci, Tarih Alanındaki Kullanıcıların Bilgi Gereksinimleri ve Bilgi Kullanım Özellikleri, Hacettepe Üniversitesi Sosyal Bilimler Enstitüsü Bilgi ve Belge Yönetimi Anabilim Dalı Yüksek Lisans Tezi, Ankara, 2006, s.37.

2 “Bibliyografik Denetim", http://acikders.ankara.edu.tr/mod/resource/view.php?id=397 
araştırma sahası olan Macar ve Türk ilişkilerinin tarihi sürecine ışık tutmaya çalışan Türkçe olan çalışmaları derlemeye çalıştık. Bunu yaparken, tez ve araştırma eserlerini çalışmamız dışında bırakıp, sadece makaleleri derledik. Dolayısıyla bu kaynakça, ileride yapılacak yeni çalışmalara kolaylık sağlayacaktır. Bu konu üzerinde bugüne kadar bir bibliyografya çalışması yapılmadığını da vurgulamak çalışmanın hususiyeti açısından önemli olacaktır.

Türk-Macar çalışmalarına küçük de olsa bir katkıda bulunabilmek en büyük temennimizdir.

ÁGOSTON, Gábor; “ Siyaset ve Histografi: Macaristan’da Türk ve Balkan Çalışmalarının Gelişimi ve İstanbul'daki Macar Araştırma Enstitüsü”, Türkler, Cilt: 15, Yeni Türkiye Yayınları, Ankara 2002, s.92-98.

; "XVI. Yüzyılda Macaristan'da Osmanlı Barut Üretimi: Budin Baruthanesi", Belleten, Cilt:67, Sayı:249, Yll:2003, ss.541-552.

AKIN, Hicran; "Németh'e Göre En Eski Türk-Macar Münasebetleri”, Ankara Üniversitesi Dilve Tarih-Coğrafya Fakültesi Dergisi, Cilt:XXX, Sayı:1-2, Yıl:1982, s. 1-6.

AKSEL, Sevgi Can Yağcl; "Türk Basınında 1956 Macar İhtilali: Hürriyet, Cumhuriyet, Ulus ve Zafer'de Haber Sunumuna İlişkin Uzlaşma ve Ayrışmalar”, İletişim Kuram ve Araştırma Dergisi, Sayı: 39 / Güz 2014, s. 90-112.

ALTAYLI, Yasemin; “VasárnapiUjság Örneğinde Macar Basınında I. Dünya Savaşı’nın İlk Yansımaları ve Osmanlı Devleti'nin Savaşa Girmesi”, Çanakkale Araştırmaları Türk Yıllı̆̆ı, Y. 13, S. 19 (Güz 2015) , s.65-91.

Mart 2016, s. 64-69.

; “ Budin Paşalarının Macar Dilinin Teşviki ve Dini Hoşgörüsü”, 2023, S.59,

ATABAY Mithat; “Atatürk'ün Ankara'ya Davet Ettiği Macar Profesör AntalRehly'nin Türkiye»deki Çalışmaları", Ankara Üniversitesi Türk InkılapTarihi Enstitüsü DergisiAtatürk Yolu, C.8, Yıl.15, Sayı.29-30, Kasım-2002, s.1-14.

; “Galiçya Cephesi'nde Türk Askeri ve Türk Şehitlikleri”, Savaş Tarihi Araştırmaları Uluslararası Kongresi 100. Yılında 1. Dünya Savaşı ve Mirası 6-8 Kasım 2014 Bildiriler, C. 1, Hilal Çetin ve Lokman Erdemir (ed.), Çanakkale Valiliği Yayınları, 2015, s.525-536.

BALKAYA, İhsan Sabri; "Türk- Macar Diplomatik Ziyaretlerinin Türk Basınına Yansımaları (1930-1931)",Karadeniz Araştırmaları, S. 20, Kış 2009, s. 97-115.

BAȘTAV, Şerif; “ Macar TürkoloğuNémeth ( 1890-1976), Türk Kültürü,S. 173, Mart 1977, s.296-300.

; “ Cumhurbaşkanı Sayın Süleyman Demirel’in Macaristan Çıkarması ( 5-7 Eylül 1994)”, Türk Kültürü, S. 32, Aralık 1994, s.737-740. 
; “ Cumhurbaşkanı Süleyman Demirel'in Macaristan'a Giderken Havaalanında Yaptığı Konuşma 5 Eylül 1994”, Türk Kültürü, S. 32, Aralık 1994, s.741-742.

; “ Ankara’da Türkolog Bir Büyükelçi”, Türk Kültürü,S. 378, Ekim 1994, s. 582-587.

;; "Tarihte Türk-Macar Münasebetleri ve Macar-Türk Akrabalığı”, Tarih ve Toplum, C. 36, S. 125, 2001, s.59-65.

; “II. FerencRákóczi'nin 300. Doğum Ylldönümü”, Türk-Macar Münasebetleri,Türk-Macar Dostluk Derneği Yayınları, Ankara 2005, s. 93-97.

; “Türk Kültürüne Hizmet Eden Macarlar ÁrminVámbéry (1832- 1913)”, Makaleler 3, Berikan Yayınevi, Ankara 2005, s. 417-424.

Sayl:59, s. 4-13.

_; “Türk Kültürüne Hizmet Eden Macar Türkologlar”, 2023, Mart 2006,

BİLGE, Mustafa; “ Tekirdağ'da Bir Macar Prensi/ Prens II. FerencRakoczi”, Macar Kardeşler, ( Editör Yeliz Okay), Doğu Kitabevi, İstanbul 2012, s.61-72.

BİLGE, Sadık Müfit; “ Macaristan'da Osmanlı Hâkimiyeti ve İdari Teşkilatın Kuruluşu ve Gelişmesi”, Otam,S.11, 2000, s.33-81.

42.

; “Evliya Çelebi Macaristan'da”, Türk Edebiyatı, S. 39, Haziran 2011, s.40-

BİRİNCİ, Ali; “ Türk-Macar İlişkilerinde Kıymetli Bir İsim Sadrettin Karatay”, Macar Kardeşler, ( Editör Yeliz Okay), Doğu Kitabevi, İstanbul 2012, ss.91-98.

BİROL, Nil: “ Macaristan'da Osmanlı Çalışmaları Üzerine Bir Değerlendirme”, Türkiye Araştırmaları Literatür Dergisi, Cilt:8, Sayı:15, Yıl:2004, ss.473-512. 54.

CİHANGİR, Erol; “ Türk-Macar Buluşmaları Macar Turancılığı”, Turan, S. 1, 2005, s.43-

“ Türk-Macar Münasebetleri Bağlamında Jeopolitik Bir Tez Olarak Turancllı", Turan, S. 20, 2013, s.1-18.

ÇAMBEL, Leyla; “Atatürk ve Macarlar”, Siyah Beyaz, S. 10945, 20 Şubat 1997.

ÇALİK; Fatma; " Soğuk Savaş Döneminde Türkiye-Macaristan İlişkileri", Balkan Araştırmaları Dergisi, C. 4, S. 2, Aralık 2015, s.33-60.

ÇEÇEN, Anıl; “ Türkiye ve Macaristan”, 2023, S.59, Mart 2006, s. 36-41.

ÇERİ, Bahriye, “ AhmedVefik Paşa ve Macar Mültecilere Dair Bazı Belgeler” Macar 
Kardeşler, ( Editör Yeliz Okay), Doğu Kitabevi, İstanbul 2012, s.43-52.

ÇOBAN, Erdal; “ Kopan Sancağı'nın ( Macaristan) 16. Yüzyıldaki Ekonomik Gelişmesi Üzerine”, Otam, Sayı:17, Yıl:1991, ss.61-83.

“ Macaristan'da Protestanlığın Gelişmesi ve Osmanlı Hâkimiyeti”, Osmanlı Tarihi Araştırma ve Uygulama Merkezi Dergisi, S. 7, 1996, s.99-112.

Sayl:2, ss.413-439.

“ Türkiye'de Bir Macar Türkolog: TiborHalasi-Kun” DTCF Dergisi, Cilt:56,

ÇOLAK, Melek; "Atatürk Döneminde Kültürel, Siyasi ve Ekonomik Bakımdan Türk-Macar İlişkileri (1919-1938),Muğla Üniversitesi SBE Dergisi, Güz 2000 C.1, S.2, s.61-72.

; “ 19. Yüzyılın Sonu- 20. Yüzyıl Başlarında Türk-Macar Yakınlaşması”, Toplumsal Tarih, S.89, Mayıs 2001,s.4-10.

; “ Türk İnkılâbı'nın Macaristan'daki Yankıları (1923-1938)”, Arayışlar İnsan Bilimleri Araştırmaları, S. 7-8, 2002, s.153-159.

; “ Atatürk'ün Vefatı ve Macaristan'daki Yankıları”, Atatürk Araştırma Merkezi Dergisi, S. 57 Kasım 2003, s.1009-1016.

; “Atatürk Döneminde Türkiye- Macaristan İlişkileri (1923-1938)”, Atatürk Haftası Armağanı 10 Kasım 2004, Genelkurmay Askeri ve Tarihi Stratejik Etüt Başkanlığı Yayınları, S. 31, Ankara 2004, s.87-93.

;"Cumhuriyetin Kuruluş Yıllarında Türk Eğitim Yaşamında Macar Eğitimcilerin Yeri”,Atatürk Araştırma Merkezi Dergisi, S. 58, C. 20, Mart 2004, s.231-243.

; “Cumhuriyet'in İlk Yıllarında Türkiye- Macaristan İktisadi İlişkileri”,Askeri Tarih Araştırmaları Dergisi, Genelkurmay Askeri Tarih ve Stratejik Etüt Başkanlığı Yayınları, Yll:2, S. 4, Ağustos 2004, s.47-54.

; “Macaristan'da Revizyonizm ve Balkan Paktı Çerçevesinde TürkiyeMacaristan İliş̧kileri (1923-1939)”,Yakın Dönem Türkiye Araştırmaları, İstanbul Üniversitesi Atatürk İlkeleri ve İnkılâp Tarihi Enstitüsü Dergisi, S. 8, 2005, s. 1-14.

; " Muğla ve Çevresinde Macarlar”, Yakın Dönem Türkiye Araştırmaları, İstanbul Üniversitesi Atatürk İlkeleri ve İnkılâp Tarihi Enstitüsü, Yll. 5, S.10, 2006, s.27-43.

; “ Bir Macar Çocuğun Anılarında Atatürk”, Muğla Üniversitesi Sosyal Bilimler Enstitüsü Dergisi, Atatürk'ün Doğumunun 125. Yılı ve Cumhuriyetimizin 83. Yılı Özel Sayısı, 2006, s.95-105.

; “Macar GyulaGermanus'un Çanakkale Savașı ile İlgili Anıları", Atatürk Araştırma Merkezi Dergisi, C. XXIII, S. 67-68-69, ( Mart-Temmuz-Kasım 2007), s.133-144. 
; “ Atatürk'ün Macar Bahçıvanı JanosMathe'nin Anılarında Ankara”, Cumhuriyet Tarihi Araştırmaları Dergisi, Yıl.4, S. 7, Bahar 2008, s. 181-193.

; “ Macar Etnograf IstvánGyörffy ve Kuzey Marmara Bölgesi İnceleme Gezisi (1918)”, Belleten, C. LXXII, S. 265, Aralık 2008, s. 943-953.

; “ Türk -Macar İlişkileri ve Macaristan’ın Türk İnkılâbına Bakışı (19191938)", Türk - Macar Tarihi İlişkilerinden Kesitler, Türkiye Büyük Millet Meclisi Milli Saraylar Daire Başkanlığı, İstanbul 2009, s. 27-45.

; “ Atatürk Dönemi Türkiyesi'nde Bir Macar Meteorolog: Aksakallı HavabakanAntalRethly ( Macar Kaynaklara Göre), Cumhuriyet Tarihi Araştırmaları Dergisi, Yll. 5, S. 9, Bahar 2009, s.113-136.

; “Ístanbul Macar Bilim Enstitüsü (1916 - 1918)”, Karadeniz, S. 3, Yaz 2009, s. $91-105$. s.33-55.

; “ Atatürk ve Macar Başbakanı GyulaGömbös”, Erdem,S. 55, Aralık 2009,

; “Macar Kaynaklarına Göre Türk-Macar Askeri İlişkileri (1912-1918)”, Kuruluşundan Günümüze Türk Ordusu, On İkinci Askeri Tarih Sempozyumu Bildiriler I, Genelkurmay Askeri Tarih ve Stratejik Etüt Başkanlığı Yayınları, Ankara 2009 s.395-411

; “ II. Dünya Savaşı Yıllarında Macar Yahudileri ve Türkiye”, Karadeniz Araştırmaları, Balkan, Kafkas, Doğu Avrupa ve Anadolu İncelemeleri Dergisi, C. 7, S. 27, Güz 2010, s.77-87.

; " Atatürk, Macarlar ve Türk Tarih Tezi”, Selçuk Üniversitesi Türkiyat Araştırmaları Dergisi, S. 27, Bahar 2010, s.371-402.

; “ GyulaNemeth'in Atatürk'e Yazdığı Mektup”, Türk Dünyası Tarih-Kültür Dergisi,S. 287, Kasım 2010, s.16-18.

; “ Macar Turancıları ve Atatürk ( Macar Kaynaklara Göre)”, Türk Yurdu,C. 31, S. 21, Güz 2010, s.77-87.

; "Macar Kaynaklarında Çanakkale Savaşı",95'inci Yıl Dönümünde Çanakkale Muharebeleri ve Atatürk Sempozyumu, Genelkurmay Başkanlığı-Çanakkale 18 Mart Üniversitesi, Askeri Tarih Araştırmaları Dergisi, S. 16 (Ağustos 2010), Özel Sayı, S. $419-447$.

; “ Macar Kaynaklarına Göre GyulaAndrássy ve Osmanlı- Macar İlişkileri (1875-1878)”, Tarih İncelemeleri Dergisi, C. XXVI, S.1, İzmir 2011, s. 51-65.

; “ Macar Kaynaklarında Türk Kültürü ve Türkler ( XIX. Yüzyıl SonlarıXX.Yüzyıl Başları)”, Erdem, S. 59, Bahar, 2011, s. 107-120. 
; “Türk-Macar İlişkileri Çerçevesinde Macar Türkolojisi ve Ugor-Türk Savaşı”, IV. Uluslararası Dünya Dili Türkçe Sempozyumu, Muğla 22-24 Aralık 2011, Bildiriler, C. I, Ankara 2012, s.527,52.

; “Atatürk ve Macarlar (1914-1938)”, Turan, S. 20, Yll. 2013, s.71-80.

ÇOLAK, Melek, Sezgin Topal Mızrak, “ Macar Gençlik Heyetinin İstanbul Ziyareti (1877), Çağdaş Türkiye Tarihi Araştırmaları Dergisi, C. XVI, S. 33, Güz-2016, s.5-24.

ÇORUHLU, Tülin; “ Askeri Kültür Varlıklarında Türk-Macar İlişkileri”, Sakarya Üniversitesi Fen Edebiyat Fakültesi Fen Edebiyat Dergisi, Sayı:11, Yıl. 2009, s.130-145.

ÇULPAN,Cevdet; “Macaristan'daki Türk Kitabeleri”, Belgelerle Türk Tarihi Dergisi, Sayı:41, Yıl:1971, ss.88-90.

CSÁKi, Éva; “ Macarların Eski Tarihine, Eski-Türk Macar İlişkilerine Dair”,Türk Kültürü veHacı Bektaş Veli Araştırma Dergisi, C. IX, S. 30, Ankara 2004, s.187-191.

DAVID, Géza; “Araştırmaların İlk Evreleriyle Macaristan'da Osmanlı Tarihi”, Tarih ve Toplum Yeni Yaklaşımlar, Cilt:36, Sayı.215, Yll:2001,ss.303-305.

;“Budapește LorándEötvös Üniversitesi Türkoloji Bölümü”, Türk-Macar Tarihi İlişkilerinden Kesitler, TBMM Milli Saraylar Daire Başkanlığı, İstanbul 2009, s.19-25.

; “Arşiv Belgelerinde Macaristan'ın Osmanlı İmparatorluğu ve Türkiye'yle İlişkileri", Avrupa Arşivlerinde Osmanlı İmparatorluğu, Yonca Köksal ve Mehmet Polatel (ed.), Ankara, VEKAM Yayınları Araştırma Dizisi II, s.133-148.

; “Macaristan'da Yönetici Osmanlı Aileleri”, Otam, Sayı:38, Yll:2015, s.13-30.

2002.

; “Osmanlı Kültürünün Macaristan'daki Yayılışı ve Etkisi”, Bilig, Sayı. 20, Kış

DEMİ, Necati; “ Türkiye'de Hun-Macar İzleri ve Yerleşimleri”, Turan, S.20, Yıl. 2013, s.65-70.

DEVELIOĞLU, Sunahan; “Bir Macar Mülteci Öyküsü”, Tarih ve Toplum, Cilt:36, Sayı:215, Yll:2001, ss.19-24.

DOĞAN, İsmail, “Macar Ulusal Kimliğinin Oluşumunda Türk Etkisi”, Ankara Üniversitesi Dil Ve Tarih-Coğrafya Fakültesi Dergisi,C.47, S.2, 2007, s.1-12.

DOĞRU, Halime; “Macarlar ve Macaristan'a Dair Bir Layiha”, AnadoluÜniversitesi FenEdebiyat Fakültesi Dergisi, C. 3, S. 1,1991,ss. 171-195.

ERDOĞAN, Meryem Kaçan; “ Mülteci Bir Macar Prensi ve Terekesi RakocziJoszef”, Süleyman Demirel Üniversitesi Fen-Edebiyat Fakültesi Sosyal Bilimler Dergisi, Sayı:23, 
Yll:2011, ss81-102.

EREN, Hasan, “Geçmişine Bakan Yalnız Bir Ulus: Macarlar”, Tarih ve Toplum, C. 36, S. 215, Kasım 2001, s. 76-87.

;"Balkan Ülkelerinde ve Macaristan'da Türkoloji Çalışmaları",Dünyada Türklük Araştırmaları ve Türkiye Sempozyumu (29-30 Eylül1986), Fatih Yayınevi, İstanbul-1987, s. 72-83.

; “GyörgyGyörff ( 1917-2001)", Türk Dili,S. 611, Kasım 2002, s. 961-964.

FODOR, Pál, “Ondokuzuncu Yüzyılın İlk Yarısında Macar Reform Hareketleri ve -1848 49 Devrimi”, Doğumunun 200. Yıldönümünde LajosKossuth 1848-49 Macar Özgürlük Mücadelesi ve Osmanlı-Macar İlişkileri Sempozyumu, Dumlupınar Üniversitesi, Celal İnal-Naciye Güngörmüş (der.), 15 Mart 2002, Kütahya, 2002, s. 45-53.

FEHÉR, Géza; “ Kanuni’nin Macaristan'la İlgili İki Yazıtı”,Önasya Aylık Milliyetçi Fikir ve Sanat Dergisi,S. 5, Yll. Ekim 1969.

; “Macar San'atında Türk Etkisi”, Önasya,Sayı:41, Ocak 1969, s.7-8.

; “Macar San'atında Türk Etkisi”, Önasya, Sayı:42, Şubat 1969, s.7-9.

; “ Macaristan’ın XVI-XVII Yüzyıllardaki Türk Zanaatları ve Bunların Tesiri” Önasya, S. 43, Mart 1969, s.8-9.

; “ Macaristan'ın XVI-XVII Yüzyıllardaki Türk Zanaatları ve Bunların Tesiri” Önasya,Sayı:44, Nisan 1969, s.8-9.

; “Macaristan'da XVI.-XVII. Yüzyıl'dan Kalma Türk Mimarî Anıtları”,Önasya, Sayı:45 (Mayıs 1969), s.20-22.

; “Balkanlardaki Kuyumculuğa Türk Tesiri”, Önasya, Sayı:53-54, (Ocak-Şubat 1970). 1970), s.14-15.

; “Osmanlı-Türk Kuyumculuğunun Balkanlar'a Tesiri”, Önasya, Sayı:56 (Nisan

; “Macar Milli Müzesi’nin Yeni Bir Eseri: XVI. Yüzyıl Başından Kalma Türk Deri Kaftanı", Önasya, S.57 (Mayıs 1970), s.14.

1970), s.14-15.

; “Osmanlı-Türk Kuyumculuğunun Balkanlar’a Tesiri”, Önasya, S.56 (Nisan

FEKETE, Lajos; “Osmanlı Türkleri ve Macarlar (1366-1699)”, Belleten, C. XIII, S. 52, Yıl. Ekim 1949, s. 663-743. 
GÜLEN, Yılmaz; “CsokJasa!”, Tarih ve Toplum, C. 36, S. 215, Yıl, Kasım 2001, s. 4-7.

GÜLBOY, Pınar Ekrem; “ 1956 Macar Ayaklanmasının Türkiye Basınında Yansımaları”, Macar Kardeşler, ( Editör Yeliz Okay), Doğu Kitabevi, İstanbul 2012, s.99-122.

GÖKBİLGİN, Tayyib; “Macaristan'daki Türk Hâkimiyeti Devrine Ait Bazı Notlar”, Türkiyat Mecmuası, S. 7-8, 1942, s.200-211.

12,1950, s.503-505.

; “ Osmanlı Tarihinde Türk-Macar Yakınlığı”, Yeni Tarih Dünyası, C. 2, S.

; “Macaristan'daki Türk Hatıraları", Türkiye Turing ve Otomobil Kurumu Belleteni, S. 221-222, 1960, s.3-5.

; “ 19. Asır Sonlarında Türk-Macar Münasebetleri ve Yakınlı̆̆ı”, Nemeth Armağanı, Yay. Haz. JanosEckmann, Agâh Sirrı Levend, Mecdut Mansuroğlu, TTK Yay. Ankara 1962, s.171-182.

; "RákócziFerenc II. Ve Osmanlı Devleti Himayesinde Macar Mültecileri”, Türk-Macar Kültür Münasebetleri Işığı Altına II.RákócziFerenc ve Macar Mültecileri Sempozyumu (31 Mayıs- 3 Haziran 1976), İstanbul Üniversitesi Edebiyat Fakültesi, s.1-17.

GÜLBOY, Gül Pınar Ekrem; “ 1956 Macar Ayaklanmasının Türkiye Basınındaki Yankıları”, Macar-Türk İlişkileri Üzerine Makaleler Macar Kardeşler ( Editör Yeliz Okay), Doğu Kitabevi, İstanbul 2012, s.99-122.

GÜLEN, Yılmaz; “CsokJasa!”, Tarih ve Toplum, C. 36, S. 215, 2001, s.4-7.

GÜMÜŞKILIÇ Mehmet, "Macaristan Türkoloji'si Üzerine Bir Biyo-Biyografi Denemesi”, TurkishStudies- International PeriodicalForTheLanguages, LiteratureandHistory of TurkishorTurkic, Volume 7/4, Fall-2012, Ankara-Türkiye, s.367-406.

GÜNGÖRMÜŞ, Naciye; “ 1848-1849 Macar Özgürlük Mücadelesi ve Osmanlı Macar Dayanışması", Kök İçtimai ve Stratejik Araştırmalar Dergisi, C.I, S. 12, Yıl.1999, s.127-138.

EREN, Hasan; "Macar Bilimler Akademisi Şeref Üyeliğine Seçildi”, Türk Dili Dil ve Edebiyat Dergisi, C. LV, S. 438, Haziran 1988, s.351.

GÜRKAN, Nesrin, “Tarihteki Macar Misafirlerimiz”, 2023, S.59, 15 Mart 2006, s.52-57.

HALASİ-Kun, Tibor; “ Türk-Macar Akrabalığı Üzerine”, Çev: Erdal Çoban, Erdem, C.VI, S.18, 1990, s. 885-892.

HAZAI György, “Macaristan'da Türkoloji”, Türk Dili, S. 461, Mayıs-1990, s.201-210.

; “Türkoloji’nin Türkiye'de Cumhuriyet Dönemindeki Gelişmesinin Bazı Sorunları Üzerine”, I. Uluslararası Türkoloji Kongresi Bildirileri-Atatürk'ün 120. Doğum 
Yıldönümü’ne Armağan, Atatürk AraştırmaMerkezi, Ankara-2001, s.153-163.

; “ Macar Tarihi Türk Tarihi İçin Neler Öğretiyor? Kroniğin Yazması ve Yazarı", Tarih ve Toplum, C. 36, S. 215, 2001, s.87-91.

IŞIK, Mustafa; “Mohaç Savaşı ve Budin'de Osmanlı Hâkimiyeti'nin Tesisi Meselesi (15261541)”, Uluslararası Sosyal Araştırmalar Dergisi, C.5, S.22, Yaz 2012, s.270-279.

; “BudinSancağı'nda Tımar Rejimi: 1561-1560 Yılı Örneği», HistoryStudies International Journal of History, Vol.5, No.4 ,July 2013, s.177-187.

HORVATH, Jozsef; “ Macaristan'da İbrahim Müteferrika”, Tarih ve Toplum, C. 36, S. 215, 2001, s.51-58.

KARAMANLIOĞLU, Ali; “ Eckmann Hoca”, Türk Dili ve Edebiyatı Dergisi, 1975, s.1314.

KARBİ, Bilge; “ Birinci Dünya Savaşı'nda Osmanlı Devleti ve Avusturya-Macaristan Askeri Yardımlarına Bir Örnek: Osmanlı Birliklerinin Galiçya Cephesi'ne Gönderilmesi Kararı Etrafındaki Tartışmalar", Çanakkale Araștırmaları Türk Yıllığı, Yıl. 4, S. 20, Bahar 2016, s. 193-206.

KADIOĞLU, Muhsin; "Budapește(Budin) Kalesinde Türklerden Kalan Hatıralar”, Türk Dünyası Tarih ve Kültür Dergisi, S. 301, İstanbul Ocak 2012, s. 35-44.

KAKUK, Zsuzsa, “Türk Kültür Etkisinin Macar Dilindeki Yansıması”, IX. Türk Tarih Kongresi 21-25 Eylül 1981, C.III, TTK, Ankara 1989, s.1223-1227.

Araștırmaları Yıllığı Belleten, 1968, s.65-80.

KELLER, Bela; “ Macar İhtilalinin 8. Yıldönümü”, ( çev. Şerif Baştav), Türk Kültürü, S. 24, Ekim 1964, s.55-64.

KOŞAY, Hamit Zübeyr; “ Macaristan'daki Türkoloji Tedkikatına Tarihi bir Atf-ı Nazar”, Milli Mecmua, Yıl.1, S. 5, s.71-72.

; “ Türk Macar Kardeşliği”, Türk Yurdu, C. 5, S. 35, Yıl. 1930, s.54-55.

;“ Türkolog ve BizantologGezaFeher'in Hayatı ve Eserleri”, Belleten, C. XIX, S. 76, Ekim 1955, s.529-540.

KORKMAZ Zeynep, “Türk Macar İlişkilerinde Türklük Bilimi(Türkoloji)’nin Yeri”, Türk Dili Dil ve Edebiyat Dergisi, S. 722, Şubat-2012, s. 152-156. 71-74.

KUŞÇU, Ayșe D.;"Prof. Dr. Mekki Şerif Baştav”, Türk Yurdu, Aralık 2010, C. 30, S. 280, s. 
KÜTÜKOĞLU, Mübahat S. ; "Prof. M. Tayyib Gökbilgin'inArdından”, İstanbul Üniversitesi Tarih Enstitüsü Dergisi Prof. M Tayyib Gökbilgin Hatıra Sayısı, İstanbul 1982,s.1-2.

; “Türkiye'de İkinci Kuşak Bir Macar: Mimar ŞandorHandi”, Toplumsal Tarih Dergisi, S.206, Şubat 2011, s.84-88.

MALKOÇ, Emin; “Türk-Macar Akademik İlișkilerinde Erken Cumhuriyet Döneminden Bir Kesit: Macar Profesörlerin 1924 Türkiye Gezisi”, Macar Kardeşler, ( Editör Yeliz Okay), Doğu Kitabevi, İstanbul 2012, s.81-90.

MARACZ, Laszlo; “ Ugor- Türk Savaşı ve Macar Dilinin Kökeni”, Turan,S. 20, Yıl. 2013, S.81-90.

MOLNAR, Jofez; “Mimar Sinan'ın Macaristan'daki Eserleri İzinde Araştırmalar”, Önasya, Hamit ZübeyrKoşay (çev.), S.78-77,0cak-Şubat 1972, s.8-9.

; "XVI. ve XVII. Yüzyılda Budin Şehrindeki Gemili Köprü", Önasya, Hamit ZübeyrKoşay (çev.), S.71-70, Haziran-Temmuz 1971, s.10-11.

NAMAL, Yücel; “ Zonguldak'ta Macar Uzmanlar (1923-1950)”,Karaelmas Medya ve Kültür, Nurçay Türkoğlu, Sevilen Toprak Alayoğlu (der.) İstanbul 2009, s.97-108.

" Prof. Arminus ( Hermann) Vambery ve Ermeni Meselesi", Ermeni Araştırmaları Dört Aylık, Tarih, Politika ve Uluslararası İlişkiler Dergisi,S. 39, Yıl. 2011, s.213-232.

206, Şubat 2011, s.84-89.

; “ Türkiye'de İkinci Kuşak Bir Macar: Mimar Şandor Hadi”, Tarih ve Toplum,S.

; “ Macar TükologGyulaMeszaros ve Türkiye'deki Çalışmaları”, XI. Milli Türkoloji Kongresi Bildirileri 11-13 Kasım 2014, C. 2, İstanbul 2015, s.621-653.

; “I. Dünya Savaşı Sırasında Macar Gazeteci Istvan (Dobai) Dobay’ın İstanbul ve Çanakkale Cephesindeki İzlenimleri (1915)", 7. Uluslararası Balkanlarda Sosyal Bilimler Kongresi Bildirileri, Recai Coşkun, Sevda Yaşar Coşkun, Samet Güner, Naciye Güliz Uğur, Muhammed Kürşad Uçar (ed.), Aralık 2015, s.270-281.

s.2146-2152.

; “Attila Orbok ve Ermeniler”, Yeni Türkiye,S. 62, Yıl. 20, Eylül-Aralık 2014,

; “ I. Dünya Savașı Sırasında Avusturya-Macaristan Gazetecilerinin İstanbul ve İzmir Ziyaretlerinin Osmanlı Basınına Yansımalar ( 31 Mayıs-11 Haziran 1918)”, Yeni Türkiye,S.65, Yıl.21, Ocak-Şubat 2015, s.1363-1374.

NAGY, Gyula; “Macaristan'da 16. Yüzyılda Türk Yönetimi”, Güney-Doğu Avrupa Araştırmaları Dergisi, S. 8-9, 1979, s.301-306. 
NAGY KINCSES Éva “ Macar Türkoloji'sinin Aktüel Görevleri”, Yeni TürkiyeDergisi, Yll.8, S. 43, Ocak- Şubat-2002, s. 49-51.

NAZIR, Bayram; " Osmanlı Devleti'nin Aldığı Tedbirler ve Kütahya'dan LajosKossuth’u Kaçırma Girişimleri”, Tarih ve Toplum Dergisi, C. 36, S. 215, 2001, s.15-18.

; “ Macar Mültecilerin Osmanlı Devleti'ndeki Gündelik Hayatları”, LajosKossuth'un Doğumunun 200. Yıldönümünde LajosKossuth ve 1848-1849 Osmanlı Macar İlişkileri, Ed: Celal İnal-Naciye Güngörmüş, Dumlupınar Üniversitesi Yayını, Kütahya 2002, s. 55-63.

; “ Macar ve Polonyalı Mültecilerin Osmanlı Devleti'ne Sığınmaları ve Diplomatik Kriz", Türkler,C. 12, Ankara 2012, s.813-825.

; “ II. Abdülhamid Dönemi Osmanll-Macar Dostluk İlişkileri”, Atatürk Üniversitesi Türkiyat Araştırmaları Enstitüsü Dergisi, S. 43, Erzurum 2010, s.309-317.

NYİRI, Mária T. ; “ Oldukça Uzak Geçmişten Başlayarak 1996’ya Kadar Tarih Boyunca Türk-Macar İlişkilerine Kısa Bir Bakış”Türk Dünyası Tarihi Araştırmaları Dergisi, S. 149, Mart-Nisan 2004, s.211-222.

; “ Macaristan'da Türkolojinin Tarihi-I”, Türk Dünyası Araştırmaları Dergisi, S. 139, Ağustos 2002, s.201-210.

OKAY, Cüneyt; “Türk Derneği Dergisi ve Birinci Dünya Savaşı Öncesi Macaristan'daki Türkoloji Çalışmaları", Macar Kardeşler: Macar-Türk İlişkileri Üzerine Makaleler, ( Editör Yeliz Okay), Doğu Kitabevi, İstanbul 2012, s. 53-60.

OKAY, Yeliz; "Hüseyin Namık Orkun'un Macaristan Türkoloji Ekolüne Dair Yazıları Çığır Dergisi Örneği”, Macar Kardeşler: Macar-Türk İlişkileri Üzerine Makaleler, ( Editör Yeliz Okay), Doğu Kitabevi, İstanbul 2012, s. 123-131.

ÖNEN, Nizam; “Turan'a İki Farklı Yol: Macar ve Türk Turancılıkları”, Modern Türkiye'de Siyasi Düşünce, C. 4, İletişim Yayınları, İstanbul 2003, s.406-408.

; “ Budapește'de Bir Türk İmam Abdüllatif Efendi'nin Hayatı”, Toplumsal Tarih, C. 27, S. 160, Nisan 2007, s.78-81.

ÖNCÜ, Ali Servet ; “Türk Kaynakları Işığında Son Avusturya-Macaristan İmparatoru Karl'ın İstanbul Ziyareti”, CTAD, Y.9, S.17, Bahar 2013, s.57-76.

ÖNSOY, Murat; «Avusturya-Macaristan İmparatorluğu^nda Milliyetçilik Hareketleri», Balkanlar El Kitabı, C. I, Bilgehan Gökdağ- Osman Karatay (haz.), Akçağ Yayınları, Gözden Geçirilmiş 2. Baskı, Ankara, s. 435-446.

ORTAÇ, Hilmi; "Macar Basınında Kurtuluş Savaşı ve Atatürk”, Tarih ve Toplum, C. 36, S. 215, 2001, s.8-14. 
ÖZARSLAN, Metin; “Bela Bartok'un Türkiye'deki İlk Haftası ve Matbuattaki Akisleri Üzerine”, Turan,S. 20, Y. 2013, s.95-102.

ÖZÇELİK, Mücahit, “Avusturya-Macaristan İmparatoru'nun 1918 İstanbul Ziyaretinin Türk Basınına Yansımaları”, SDÜ Fen Edebiyat Fakültesi Sosyal Bilimler Dergisi, S. 27, Aralık 2012, s.51-63.

ÖZGİRAY,Ahmet; “Türkiye-Macaristan Siyasi İlişkileri (1938-1923)”, Tarih İncelemeleri Dergisi, C. XII, S. 97, s.76-80.

ÖZKAN, Selim Hilmi; “ Karlofça Antlaşması Sonrası Osmanlı-Avusturya İlişkilerinde Macarların Durumu", Avrasya Etütleri Dergisi, S. 41, Ankara 2012, s. 183-195.

ÖZTÜRK, Cemil; "113 Yıl Önceki Bir Türk Heyetinin Macaristan Gezisi”, Tarih ve Toplum, C. 14, S. 83, Kasim 1990, s.52-55.

S. $53-\overline{56}$.

“Macarlarla Kardeşmiyiz?”, Tarih ve Toplum, C. 18, S. 105, Yll. Eylül 1992,

PARLATIR, İsmail; “ Macaristan'da Türk Kültürünün İzleri”, Atatürk Üniversitesi Türkiyat Araştırmaları Enstitüsü Dergisi,S. 39, Erzurum 2009, s.235-240.

PİRALI, Sadettin; “ Macar Kaynaklarına Göre Mohaç”, Hayat Tarih Mecmuası, S. 2 Şubat 1978, s.42-46.

RÁSONYI, László; “Türk-Macar İlişkilerinin Kaynakları”, Belgelerle Türk Tarihi Dergisi ( Dün/Bugün/Yarın), S. 41, 1971, s.64-73.

; "Atatürk Özgürlük Savasının Macar Basınında Yankıları",Belleten, Cilt: XLV/1, Say: 177, Yll. Ocak 1981, s. 79-86.

ULLEIN-REVICZKY, Antal; “ Türkiye'de Macar Hatıraları”, Tarih Mecmuası,C. 2, Say: 7, Ağustos 1972, s.45-52.

SARAL, Emre; “ Atatürk ve Macarlar”, Genç Akademisyenlerin Gözüyle Tek Adam: Mustafa Kemal Atatürk ( Sempozyum Bildirileri Kitabı), 21 Kasım 2008, Temuçin F. Ertan, Kadri Unat, Çiğdem Kılıçoğlu ( Haz.), Ankara Üniversitesi Türk İnkılâpTarihi Enstitüsü, Ankara 2012, s.143-152.

“ Yakın Dönem Türkiye-Macaristan İlişkileri”, Mavi Elma: Türkiye Avrupa İlişkileri, Ozan Ömerci ve Hüseyin Işıksal (der.), Gazi Kitabevi, Ankara 2016, s. 725-776.

SARAL, İsmail Tosun; " Türkoloji'nin Öncüsü Vambery Sultan Abdülhamid'in İngiliz ve Alman Siyasetini Anlatıyor”, Düşünce ve Tarih Dergisi, Yll. 2, S. 13, Ekim 2015, s. 36-46. 
Ağustos 2016, s. 50-56.

; “ Macarlar, Türkler ve Atatürk”, Düşünce ve Tarih Dergisi, S. 23, ;; “ 1956 Macar İhtilali ve Türk Şairler”, Düşünce ve Tarih Dergisi,S. 25, Ekim 2016, s. 48-54.

; “ÁrminVámbéry”, 2023, S. 162, 15 Ekim 2014, s.76-80.

Mart 2016, s.58-63.

;" Macaristan'da Osmanlı Kültür Temsilcisi: Gül Baba", 2023, S. 59,

SEREZ, Mehmet, "Tarihte Türk-Macar İlişkileri”, Türk-Macar Münasebetleri Işı̆̆ı Altında II. RakocziFerenc Ve Macar Mültecileri Sempozyumu, Celâl İnal (haz.), Ankara, Macaristan Cumhuriyeti Büyükelçiliği, İkinci Baskı, Haziran 2003, s.67-93.

SİPOS, János "Macarların Türk Halkları Arasında Gerçekleştirdiği Halk Müziği Araştırmaları”, Türk Kültürü ve Hacı Bektaş Velî Araştırma Dergisi, S.30, 2004.

SOFUOĞLU, Ebubekir; “ Abdülmecid ve Macar Mülteciler”, Tarih ve Toplum, C. 36, S. 215, 2001, s.41-46.

SOĞUKÖMEROĞULLARI, Mehmet; “ Ziyaeddin Fahri Fındıkoğlu'nun "Pește Turan Cemiyeti” Yazısı ve Düşündürdükleri”, Turan, S. 20, 2013, s.39-50.

SOYSAL, İsmail; "Mohaç Sonrası Türk-Macar Siyasal İlişkileri Üzerinde Macar Tarihçisi GézaPerjés'in Bir Değerlendirmesi”, Belleten, S. 157, C. XL, Ocak 1976, s. 127-138.

SUNAR, Burcu; YOLCU, Serap; “Orta Avrupa'da Yalnız Bir Asyatik Devlet: Macaristan (1848-1943)”, Macar Kardeşler,( Editör Yeliz Okay), Doğu Kitabevi, İstanbul 2012, s. 151173.

SZÉKELY, Maria Német; "Macar-Türk Tarihi İlişkileri”, Türk-Macar Tarihi İlişkilerinden Kesitler, Milli Saraylar Daire Başkanlığı, Haz. T. Cengiz Göncü, İstanbul 2009, s. 13-17.

TALAY, Birsen, “ Cebimde Çok Küçük Elma Var”, Tarih ve Toplum, C. 36, S. 215, Yıl:2001, s.38-40.

TARHAN, Nazım; “ Tarihte, Türk-Macar Toplumsal Münasebetleri”, Görüşler, C. 8, S. 7980, 1945, s. 5-6.

TASNÁDİ, Edit; “Macaristan'daki Türk Tarihi Anıtları”, Türk Kültürü, C. 33, S. 389, 1995, s. 54-59.

; “ Macaristan'da Türk Edebiyatı”, Türk Kültürü, S. 398, Yıl. XXXIV, Haziran 1996, s.371-375.

;; “ Budapeşte Üniversitesi'nde Türkoloji 125 Yıllık”, Türk Kültürü, S. 400, 
Yll. 34, Ağustos 1996, s.54-55.

;; “18. Ve 19. Yüzyılda Osmanlı'da Macar Mültecileri”, Tarih ve Toplum, C. 36, S. 215, 2001, s. 71-75.

;“Macar Medyasında Atatürk İmajı”, Uluslararası Atatürk Kongresi 2003, Atatürk Araştırma Merkezi, 2005, s. 361-370.

; “Genç Türkiye Cumhuriyeti’nde Bir Macar Generali: Albert Bartha”, XV. Türk Tarih Kongresi Ankara: 11-15 Eylül 2006,Atatürk ve Türkiye Cumhuriyeti Tarihi, C.V, Ankara, 2010, s.2387-2393.

TEKIN, Emrullah; “ Ermeni Meselesiyle İlgili II. Abdülhamid'in Vambery'e Cevabi Bir İradesi”, Türk Dünyası Araştırmaları, S. 76, Şubat 1992, s.145-149.

TEKINDAĞ, Şahabettin; “Türk-Macar Münasebetlerine Toplu Bir Bakıs”, Türk-Macar Kültür Münasebetleri Isığı Altında II. RákóczıFerenc ve MacarMültecileri Sempozyumu (31 Mayıs-3 Haziran), İstanbul Üniversitesi EdebiyatFakültesi, İstanbul 1976, s. 152-159.

TEKINSOY, Yunus Emre, “I. Dünya Savaşı'nda Türk-Macar İlişkilerine Bir Örnek: Macar Turan Cemiyeti ve Türk Ocağı”, 100. Yılında I. Dünya Savaşı Uluslararası Sempozyumu: Bildiriler, Budapeşte 3-5 Kasım 2014, Atatürk Araştırma Merkezi Yayınları, 2015, s.233256.

TURAN, Namık Sinan; “ Kanuni'nin Macaristan Siyaseti: Macaristan'da Osmanlı Kültüründen İzler", Toplumsal Tarih, S. 138, Yıl. 2005, s.46-53.

; “1699 Karlofça’ya Kadar Orta Avrupa'da Bir Osmanlı Üssünün Tarihi: Macaristan”, Macar Kardeşler,( Editör Yeliz Okay), Doğu Kitabevi, İstanbul 2012, s.9-30.

TİRYAKİĞLU, Ethem; “ Dünkü ve Bugünkü Türk-Macar İlişkileri”, Silahlı Kuvvetler Dergisi, Yıl. 96, S. 263, Eylül 1977, s.39-53.

TOROS, Taha; “ Türk-Macar Münasebetleri”, Türkiye Turing ve Otomobil Kurumu Belleteni, Nisan-Mayıs, No: 267-268, İstanbul 1964, s.18-20.

TOTH, İmre; “Macar İhtilalinin 12. Yıldönümü Münasebetiyle Büyük Devlet Adamı Atatürk Ve Türk-Macar Kardeşliği”, Önasya, S.38, Ekim 1968, s.23.

;; “ Türk-Macar Kardeşliği”, Türk Dünyası, S. 6, 1971, s. 21-24.

TUNALI, Tahsin; “ Büyük Türk Hükümdarı Kanuni Macaristan ve Avusturya'da”, Hayat Tarih Mecmuası, C. 1, S. 2, 1968, s.18-22.

UÇAN, Ali; " Türk-Macar Kültür/Müzik İlişkilerine ve Türk-Macar Karşılaştırmalı Halk Müziği Araștırmalarına Bir Bakıș”, Türk-Macar Halk Müziğinin Karşılaştırmalı Araştırması, Macaristan Cumhuriyeti Ankara Büyükelçiliği Yayını, Ankara 2005, s. 88 -46. 
ÜNALP, Rezzan, “I. Dünya Savaşı'nda Macar Birliklerinin Türk Ordusuna Katkıları Çerçevesinde Kanal, Sina Ve Filistin Cephelerine İlişkin Askerî, Taktik Ve Stratejik Yaklaşımlar”, 100. Yılında I. Dünya Savaşı Uluslararası Sempozyumu: Bildiriler, Budapește3-5 Kasım 2014,Atatürk Araştırma Merkezi Yayınları, 2015, s.203-232.

YILDIRIM, Seyfi; “Cumhuriyet Döneminde Türk-Macar İlişkileri Çerçevesinde İstihdam Edilen Macar Uzmanlar”, Cumhuriyet Tarihi Araştırmaları Dergisi/ CTAD, Yıl. 8, S. 15, Bahar 2012, s.121-150.

YUSUFOĞLU, Hicran; “ Macaristan'daki Türk Kültür Anıtları”, Türk Kültürü, C. 33, S. 383, 1995, s.23-36.

37. “Osmanlı-Macar İlişkileri”, Tarih ve Toplum, C. 36, S. 215, 2001, s. 2514-25. ; “Tarihten Günümüze Türk-Macar İlişkileri”, 2023, S. 59, Mart-2006, s.

ZİMONYİ, István; “ Macaristan'daki Türkoloji Çalışmaları”, Yeni Türkiye Dergisi, Yıl. 8, S. 43, Ocak-Şubat 2002, s.46-48.

(Yazar Belirtilmemiş), "Macaristan'da Türk Tarihine Dair İntişar Eden Yeni Bir Eser”, Türk Yurdu, C. 2, S. 8, 1928, s.20-22. s.17.

(Yazar Belirtilmemiş), “ Türklerle İlgili Macar Kitapları”, Önasya, C. 6, S. 67-68, 1967,

(Yazar Belirtilmemiş), “ Macar Musikisinin Türk Kökleri”, Musiki Muallim Mektebi Talebe Mecmuası, S. 1,1936, s. 5-6. 